\title{
EVENTOS INTERACIONAIS E EVENTOS DE LETRAMENTO: UM EXAME DAS CONDIÇÕES SOCIAIS E SEMIÓTICAS DA ESCRITA EM UMA TURMA DE EDUCAÇÃO INFANTIL
}

\author{
Maria Lúcia Castanheira* \\ Vanessa Ferraz Almeida Neves* \\ Maria Cristina Soares de GouvêA ${ }^{* * *}$
}

RESUMO: Neste texto, examinamos as condições sociais e semióticas em que a escrita se faz presente no cotidiano de uma turma da educação infantil de uma escola pública em Belo Horizonte, por meio da análise de eventos interacionais e de letramento identificados nesse contexto. Os eventos analisados integram o banco de dados de uma pesquisa que envolveu a observação participante e adotou as abordagens da etnografia interacional e da sociologia da infância no exame de como, quando e por quem atividades com a escrita eram iniciadas e desenvolvidas na turma observada. A contraposição de diferentes formas de análise e de representação da interação entre participantes em eventos de letramento evidenciou que ora a professora, ora os alunos tornavam a escrita integrante das interações estabelecidas entre eles. Além disso, foi possível reconhecer aspectos que contribuem para a ocorrência de situações de incompreensão entre os participantes do grupo. O engajamento das

* Doutora em Educação e professora titular da Faculdade de Educação da Universidade Federal de Minas Gerais (UFMG).E-mail: lalucia@gmail.com

** Doutora em Educação e professora adjunta da Faculdade de Educação da Universidade Federal de Minas Gerais (UFMG). E-mail: vfaneves@gmail.com

*** Doutora em História da Educação e professora associada da Faculdade de Educação da Universidade Federal de Minas Gerais (UFMG). E-mail: crisoares43@yahoo.com.br Apoio autoral: Capes, CNPq, Fapemig e Prefeitura Municipal de Belo Horizonte.

Cad. Cedes, Campinas, v. 33, n. 89, p. 91-107, jan.-abr. 2013

Disponível em <http://www.cedes.unicamp.br> 
crianças nos eventos de letramento permite argumentar que há um esforço, individual e coletivo, das mesmas em se posicionarem como leitoras e escritoras no espaço da sala de aula.

Palavras-chave: Letramento. Educação infantil. Etnografia interacional.

INTERACTIONAL EVENTS AND LITERACY EVENTS:

EXAMINING THE SOCIAL AND SEMIOTIC CONDITIONS OF WRITING IN A KINDERGARTEN CLASSROOM

ABSTRACT: In this text we examine the social and semiotic conditions in which writing is present in the everyday school life of kindergarten, by analyzing the interactional and literacy events identified in a group of kindergarten students in a public school in Belo Horizonte. The events herein analyzed integrate the data bank of a research project that involved participant observation and adopted the approaches of Interactional Ethnography and childhood Sociology in examining how, when and by whom the activities involving written language were initiated and developed in the group we observed. The contraposition of different ways of analysis and representation of the interactions among the participants in literacy events demonstrated that sometimes the teacher, sometimes the students used writing as an integral part of their interactions. Additionally, it was possible to recognize aspects that contribute to the occurrence of lack of comprehension among the group participants. The engagement of the children in literacy events allows us to argue that there is an effort, both collective and individual, for them to position themselves as readers and writers in the classroom environment.

Key words: Literacy. Early childhood education. Interactional ethnography.

\section{Introdução}

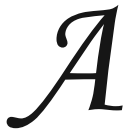

entrada em uma instituição de educação infantil possibilita à criança participar da construção de uma gama variada de interações sociais. Cada criança irá inserir-se nessas interações de uma maneira particular, criando e recriando significados sobre si mesma, sobre os outros, a escrita e outros artefatos culturais, e sobre os contextos sociais dos quais participa (CORSARO, 2005). Nas últimas décadas, vários autores destacaram a centralidade da escrita na construção de identidades e suas relações com formas variadas de inserção e participação na vida cultural e 
social. Recentemente, o interesse pelo exame do lugar da escrita no cotidiano de instituições de educação infantil foi reacendido com a promulgação da Lei Federal n. 11.274 (BRASIL, 2006), que ampliou o ensino fundamental brasileiro para nove anos, e da Lei Federal n. 12.796 (BRASIL, 2013), que prevê a obrigatoriedade escolar para pessoas de 4 a 17 anos. Diversos autores têm se dedicado a examinar essa questão (BRANDÃO; ROSA, 2010; BRASIL, 2009a, 2009b; CAMPOS, 2009; KRAMER, 2010; NEVES; GOUVEA; CASTANHEIRA, 2011).

Neste texto, buscamos refletir sobre essa temática por meio da análise de eventos de letramento (HEATH, 1983; STREET, 1984, 2005) identificados durante o desenvolvimento de uma pesquisa de abordagem etnográfica sobre a transição da escola de educação infantil para o ensino fundamental, situação vivida por crianças de meios populares (NEVES, 2010). Por meio dessa análise, busca-se examinar o papel desempenhado pelas crianças nos processos de construção de práticas letradas na turma de educação infantil investigada.

A pesquisa e seus participantes: situando a análise apresentada nesse texto

Os eventos de letramento analisados neste texto integram o banco de dados do estudo realizado durante o ano de 2008 (educação infantil) e no primeiro semestre de 2009 ( $1^{\circ}$ ano do ensino fundamental). Neste texto privilegiaremos eventos de letramento ocorridos em uma turma de educação infantil, composta por dez meninos e onze meninas com idade entre 4 e 5 anos e 6 meses. A maioria das crianças pesquisadas reside nas vilas empobrecidas ao redor do bairro de classe média onde a escola de educação infantil se localiza. A professora da turma, Paula, trabalha nessa escola desde 1997, data da sua fundação. As crianças tinham três horas semanais de aulas de artes com outra professora, Júlia. Os eventos de letramento analisados a seguir ocorreram em uma dessas aulas. Conforme depoimento dado em entrevista, o trabalho de ambas centrava-se no desenvolvimento das habilidades de socialização das crianças, tais como autonomia, negociação de conflitos, ajuda mútua, construção da história do grupo e sua coesão.

O banco de dados inclui anotações no diário de campo; gravações em vídeo das salas de aulas; gravações em áudio de entrevistas informais e semiestruturadas com professoras, crianças e suas famílias; e artefatos escritos 
usados e/ou produzidos nas salas de aula. Esse estudo de caso foi orientado por princípios da abordagem Etnográfica Interacional (CASTANHEIRA et al., 2001) e da Sociologia da Infância (CORSARO, 2005).

As análises realizadas a partir da exploração dessas abordagens teóricas levaram à construção de casos expressivos ${ }^{1}$ (MITCHELL, 1984; CASTANHEIRA, 2004), ou seja, casos etnograficamente identificados que são analisados de forma pormenorizada e refinada, com o objetivo de evidenciar as condições semióticas e sociais de sua ocorrência e fornecer elementos para a produção de inferências teóricas necessárias à construção de conhecimento sobre determinado tema. Neste texto, o dia 25 de agosto de 2008 será analisado com o objetivo de conhecer as condições semióticas e sociais, nas quais a escrita se faz presente no cotidiano da turma da educação infantil, e o papel desempenhado pelas crianças na construção dessas condições. A partir dessa análise, buscaremos apontar elementos a serem considerados no debate sobre o lugar da escrita em instituições de educação infantil.

Eventos interacionais e eventos de letramento na turma da educação infantil

Nesta seção buscaremos, primeiramente, caracterizar a dinâmica das atividades cotidianas desenvolvidas pelos participantes da turma observada para, em seguida, analisar eventos de letramento ocorridos no dia 25/08/2008. Para situarmos essa data no fluxo de atividades desenvolvidas pelo grupo, retomamos a análise do tempo gasto pela turma com atividades educativas, no decorrer dos 69 dias de observação realizada durante o ano letivo. Durante esses dias, as brincadeiras, com ou sem orientação direta das professoras, ocuparam de $26 \%$ a $64 \%$ do tempo total das atividades desenvolvidas pelo grupo. As rodas de conversa também tiveram presença significativa, ocupando de $5 \%$ a $25 \%$ do tempo total das atividades desenvolvidas. Esses dados sugerem uma ênfase em atividades de socialização das crianças, por meio do desenvolvimento das brincadeiras e rodas de conversas, e podem sugerir que a escrita não estaria presente de maneira significativa no cotidiano do grupo.

Entretanto, tal suposição pode ser facilmente contestada pela análise do Mapa dos Eventos Interacionais ${ }^{2}$ - ocorridos no dia 25/08/08 - e de eventos de letramento protagonizados pelos participantes do grupo. $\mathrm{Na} \mathrm{Ta}-$ bela 1, a primeira coluna, da esquerda para a direita, indica a hora de início 
e fim das atividades desenvolvidas pela turma. A segunda coluna nomeia os eventos interacionais e o local onde estes aconteceram. Na coluna seguinte, descrevemos, brevemente, as ações realizadas pelos participantes do grupo durante esses eventos. Além disso, indicamos nessa mesma coluna, entre parênteses, os espaços interacionais ${ }^{3}$ em que tais ações ocorreram. Utilizamos, propositadamente, o gerúndio na descrição das ações dos participantes para enfatizar a capacidade de ação dos sujeitos (alunos e professoras) em realizá-las, bem como a compreensão de que a ação dos sujeitos se dá em fluxo contínuo e ininterrupto.

Ao analisar o tempo de duração dos eventos ocorridos no dia $25 / 08 / 2008$, podemos ver que a relação tempo-atividade assemelha-se àquela estabelecida nos outros dias do ano. Nesse dia, 39,2\% do tempo foram dedicados às brincadeiras, orientadas pelas professoras ou não, e 18\% foram dedicados às rodas de conversa. Dessa forma, esse dia de aula pode ser visto como representativo da dinâmica interacional estabelecida pelo grupo ao longo do ano letivo, com a presença significativa de brincadeiras e rodas de conversa.

Esse Mapa de Eventos Interacionais também evidencia que os participantes desenvolveram atividades na sala de aula, oficina de artes, pátio, banheiro e cantina, explorando os diversos ambientes da instituição. Além disso, pode se ver que o desenvolvimento das atividades envolveu espaços interacionais diferenciados: ora a turma participava em atividades coordenadas e iniciadas pela professora (P-T), orientando suas ações para a mesma e outros membros do grupo (A-P, A-A, A-G), ora os alunos desenvolviam atividades individualmente, por iniciativa própria (I), como foi o caso das ações realizadas por Marcela e Wanda, destacadas em itálico na Tabela 1. Tal aspecto indica um rol significativo de variação de demandas apresentadas às crianças para sua efetiva participação e inserção na vida cultural e social do grupo observado.

A análise das açôes desenvolvidas pelos participantes do grupo (terceira coluna da direita na Tabela 1) indica que as atividades coordenadas pelas professoras estavam relacionadas à promoção do desenvolvimento $\mathrm{e}$ exercício de noções relativas à educação e ao cuidado pessoal, à socialização e à formação para o convívio no grupo, que envolveram a aprendizagem e participação em brincadeiras, produção artística e os usos da escrita.

No contexto desses eventos interacionais foram identificados os dois eventos de letramento iniciados espontaneamente por Marcela e Wanda, 
marcados em itálico na Tabela 1 . O primeiro desses eventos ocorreu na Oficina de Artes, quando as crianças desenhavam e pintavam assentadas em torno de uma grande mesa. No decorrer dessa atividade, Marcela engajou-se na tentativa de escrever seu nome em letra cursiva. Já o evento protagonizado por Wanda ocorreu enquanto as crianças organizavam seus materiais antes de ir para o pátio. Devido ao limite de espaço, neste texto, nos deteremos na análise do evento de letramento protagonizado por Marcela.

\section{Tabela 1}

Mapa de Eventos Interacionais: 25/08/2008

\begin{tabular}{|c|c|c|}
\hline HORA & $\begin{array}{l}\text { EVENTO } \\
\text { INTERACIONAL }\end{array}$ & AÇÔES E ESPAÇOS INTERACIONAIS \\
\hline $07 \mathrm{~h} 00 \mathrm{~min}$ & $\begin{array}{l}\text { Cantiga } \\
\text { (Pátio) }\end{array}$ & $\begin{array}{l}\text { Cantando várias músicas em uma grande roda } \\
(\mathrm{P}-\mathrm{T}) \text {. }\end{array}$ \\
\hline $07 \mathrm{~h} 15 \mathrm{~min}$ & $\begin{array}{l}\text { Organização da turma } \\
\text { (Sala de aula) }\end{array}$ & $\begin{array}{l}\text { Guardando os materiais individuais na sala } \\
\text { (P-T; A-A). } \\
\text { Dirigindo-se, sem fila, para a Oficina de Artes } \\
\text { (A-A). }\end{array}$ \\
\hline \multirow{3}{*}{$07 \mathrm{~h} 40 \mathrm{~min}$} & \multirow{3}{*}{$\begin{array}{l}\text { Roda de conversa } \\
\text { (Oficina de Artes) }\end{array}$} & $\begin{array}{l}\text { Conversando sobre a seleção feminina de vôlei } \\
\text { nas Olimpíadas de Pequim (P-T; A-G; A-P). }\end{array}$ \\
\hline & & $\begin{array}{l}\text { Conversando sobre as pinturas de J.B. Lazarini } \\
\text { (P-T; A-G). }\end{array}$ \\
\hline & & $\begin{array}{l}\text { Explicando a técnica de desenho e pintura que } \\
\text { irão desenvolver na aula (P-T; A-G). }\end{array}$ \\
\hline $07 \mathrm{~h} 54 \mathrm{~min}$ & $\begin{array}{l}\text { Desenho e pintura } \\
\text { (Oficina de Artes) }\end{array}$ & $\begin{array}{l}\text { Sentando-se em mesas coletivas (A-A; A-G). } \\
\text { Conversando, desenhando e pintando com } \\
\text { colegas de mesa (A-G). } \\
\text { Escrevendo o nome em letra cursiva (Marcela) (I). }\end{array}$ \\
\hline $08 \mathrm{~h} 20 \mathrm{~min}$ & $\begin{array}{l}\text { Brincadeiras } \\
\text { (Oficina de Artes) }\end{array}$ & $\begin{array}{l}\text { Brincando após conclusão das atividades } \\
\text { (I; A-A; A-G). }\end{array}$ \\
\hline $08 \mathrm{~h} 54 \mathrm{~min}$ & $\begin{array}{l}\text { Organização de materiais } \\
\text { (Oficina de Artes) }\end{array}$ & $\begin{array}{l}\text { Organizando brinquedos e materiais de arte } \\
\text { (P-T; I; A-A). }\end{array}$ \\
\hline \multirow[t]{2}{*}{$09 \mathrm{~h} 01 \mathrm{~min}$} & \multirow{2}{*}{$\begin{array}{l}\text { Roda de conversa } \\
\text { (Oficina de Artes) }\end{array}$} & $\begin{array}{l}\text { Conversando sobre a importância de se manter } \\
\text { a Oficina de Artes organizada com a ajuda de } \\
\text { todos }(\mathrm{P}-\mathrm{T}) \text {. }\end{array}$ \\
\hline & & $\begin{array}{l}\text { Orientando cada criança a guardar algum } \\
\text { brinquedo (P-A). }\end{array}$ \\
\hline
\end{tabular}




\begin{tabular}{|c|c|c|}
\hline $09 \mathrm{~h} 20 \mathrm{~min}$ & $\begin{array}{l}\text { Recreio } \\
\text { (Pátio) }\end{array}$ & Brincando (A-A; I). \\
\hline $09 \mathrm{~h} 40 \mathrm{~min}$ & $\begin{array}{l}\text { Merenda } \\
\text { (Cantina) }\end{array}$ & Lanchando e conversando (A-A; A-G). \\
\hline \multirow[b]{2}{*}{$09 \mathrm{~h} 53 \mathrm{~min}$} & \multirow{2}{*}{$\begin{array}{l}\text { Escovação dos dentes } \\
\text { (Banheiro) }\end{array}$} & Escovando os dentes (P-T; I; A-A). \\
\hline & & $\begin{array}{l}\text { Crianças conversam e brincam entre si } \\
\text { (P-T; A-A; A-G; I). }\end{array}$ \\
\hline \multirow[b]{2}{*}{$10 \mathrm{~h} 06 \mathrm{~min}$} & \multirow{2}{*}{$\begin{array}{l}\text { Roda de conversa } \\
\text { (Sala de aula) }\end{array}$} & Lendo calendário (“Que dia é hoje”) (P-T; A-G). \\
\hline & & $\begin{array}{l}\text { Conversando sobre as brincadeiras que irão } \\
\text { desenvolver no pátio (P-T; A-G). }\end{array}$ \\
\hline \multirow[b]{2}{*}{$10 \mathrm{~h} 14 \mathrm{~min}$} & \multirow[b]{2}{*}{$\begin{array}{l}\text { Organização de materiais } \\
\text { (Sala de aula) }\end{array}$} & $\begin{array}{l}\text { Guardando os cadernos e agendas na mochila } \\
\text { (P-T). }\end{array}$ \\
\hline & & $\begin{array}{l}\text { Pegando livros (I; A-A). } \\
\text { Folheando um livro de histórias (Wanda): "E assim } \\
\text { termina a história. E viveram felizes para sempre"(I). } \\
\text { A professora comenta para a pesquisadora: "Tenho } \\
\text { que anotar isso!", em referência à fala da Wanda. } \\
\text { (P-Pe) }\end{array}$ \\
\hline \multirow[t]{2}{*}{$10 \mathrm{~h} 32 \mathrm{~min}$} & \multirow{2}{*}{$\begin{array}{l}\text { Brincadeiras } \\
\text { (Sala de aula) }\end{array}$} & $\begin{array}{l}\text { Brincando de "Acorda, Girafa" e "Quente e frio" } \\
(P-T) \text {. }\end{array}$ \\
\hline & & Avaliando as brincadeiras (P-T) (A-G). \\
\hline $11 \mathrm{~h} 20 \mathrm{~min}$ & Saída & $\begin{array}{l}\text { Pais ou mães buscam as crianças na sala de aula e } \\
\text { conversam com a professora (F-P; F-A; P-F). }\end{array}$ \\
\hline
\end{tabular}

Legenda: P-T (Professora-Turma); A-P (Aluno-Professora); A-A (aluno-aluno); A-G (Aluno - Grupo); I (aluno realizando atividades por iniciativa própria, sozinho, e sem a coordenação explicita da professora); P-F (Professora-Família); F-A (Família-aluno); F-P (Família-Professora); P-Pe (Professora - Pesquisadora).

\section{A escrita na aula de Artes}

O evento de letramento em que Marcela escreve o seu nome em letra cursiva ocorreu durante as atividades realizadas na Oficina de Artes. Nesse momento, retomamos as anotaçôes feitas por Neves em seu Diário de Campo para oferecer mais elementos sobre as condiçōes sociais e semióticas de realização desse evento de letramento.

Júlia e as crianças se dirigem para a Oficina de Artes. Às 07h40min, Júlia sentou-se com as crianças no chão para a roda de conversa que caracterizava todo início de suas aulas. Ela mostrou recortes de jornal sobre a

Disponível em <http://www.cedes.unicamp.br> 
seleção de vôlei feminino, que havia ganhado a medalha de ouro nos Jogos Olímpicos de Pequim no dia anterior. Percebe-se, aqui, como a leitura foi contextualizada pela professora. A seguir, mostrou para as crianças uma revista e conversou com elas sobre o artista plástico J. B. Lazzarini, explorando as cores usadas por esse artista em suas obras. Júlia lia os nomes das obras de Lazzarini e, aparentemente, sem serem solicitadas, as crianças repetiam esses nomes. Lúcio comenta: "Júlia, eu achei muito bonito". Algumas crianças se aproximaram para ver a revista que Júlia estava mostrando. Outras conversavam entre si. Wanda brincava com um pano preto que estava no chão. Gradativamente, o barulho das crianças conversando aumentou, parecendo indicar uma dispersão do grupo. Júlia, como sempre, explicou a técnica de artes que desenvolveriam naquele dia: as crianças iriam fazer um desenho com canetão e, após o desenho ficar pronto, elas iriam pintá-lo com guache. Às $07 \mathrm{~h} 54 \mathrm{~min}$, as crianças se sentaram nas mesas e Júlia entregou os papéis e os canetōes. As crianças se envolveram com a ação de desenhar, conversando entre si e mostrando seus desenhos umas para as outras. Enquanto isso, Júlia preparava a tinta. Marcela desenhava uma menina, colorindo seu vestido com o próprio canetão amarelo. Ao lado do desenho escreve seu nome de cor de rosa. Ela utiliza apenas letras maiusculas e tenta emendá-las, em uma imitação de uma letra cursiva. (Anotaçôes do Diário de Campo, 25/08/2008)

A análise da descrição feita por Neves em seu diário de campo recupera nuanças das atividades desenvolvidas pelo grupo que não foram representadas na Tabela 1, como a leitura de jornais e revistas pela professora como elemento de sua conversa com as crianças. Assim, pode-se reconhecer que outros eventos de letramento, ou seja, eventos em que a escrita tornou-se parte integrante da interação entre participantes, precederam aqueles protagonizados por Marcela e Wanda. Além disso, pode-se ver como a professora explorou a escrita de maneira significativa para os participantes, tanto com relação ao que acontecia fora da escola (as olimpíadas), quanto ao que seria foco da atividade escolar (obras do artista).

Neves descreveu, também, a resposta das crianças à leitura feita pela professora: Júlia lia os nomes das obras de Lazzarini e, aparentemente, sem serem solicitadas, as crianças repetiam esses nomes. $\mathrm{O}$ uso da palavra "aparentemente" indica a dúvida da pesquisadora sobre se a professora havia solicitado ou não aos alunos a repetição em coro dos nomes das obras de Lazzarini. Posteriormente, a análise das gravações em vídeo confirmou que tal solicitação não havia sido feita e sequer era uma prática usual naquela turma ou escola. Dessa forma, confirmou-se que essa repetição havia sido 
uma iniciativa dos alunos. Talvez, os alunos não tenham sido expostos a essa prática no interior dessa instituição, mas sabemos que a criança entra para a escola com uma representação do que irá encontrar naquele espaço institucional e do que é feito ali. Tal representação pode ser construída em várias outras oportunidades, como, por exemplo, os processos de preparação da criança para a entrada na escola por seus pares ou familiares (CASTANHEIRA, 1991). Ao agirem dessa forma, as crianças evocaram uma prática escolar que imprimiu uma nuança "escolarizada" à leitura de jornais e revistas trazidos à sala de aula pela professora, algo que não era sua intenção inicial.

Vimos também, pelas anotações feitas por Neves, que um dos alunos externou sua avaliação das obras do artista (Lúcio comenta: "Júlia, eu achei muito bonito") e que algumas crianças se aproximaram para ver de perto a revista, enquanto as demais se ocupavam com outras brincadeiras. As ações dessas crianças demonstram como cada uma, a seu modo, se posicionou e respondeu às proposições da professora. $\mathrm{O}$ fato de que não houve nenhuma sinalização por parte da professora de que tais comportamentos seriam inapropriados indica que haveria por parte dela a disposição de aceitar um rol variado de posicionamentos e respostas dos alunos, ou seja, uma gama variada de formas de participação.

Neves também registrou que, quando as crianças pareciam se dispersar, a professora "explicou ao grupo a técnica de artes que desenvolveriam naquele dia: as crianças iriam fazer um desenho com canetão e, após o desenho ficar pronto, elas iriam pintá-lo com guache" e, em seguida, distribuiu os materiais que seriam utilizados para realizar a atividade proposta. Com essa iniciativa, a professora delineou as expectativas em relação às formas de participação do grupo a partir daquele momento. É, pois, no decorrer do desenvolvimento dessa nova atividade de artes que Marcela protagoniza o evento de letramento que se analisará a seguir.

\section{Marcela e a professora conversam sobre o "diferente"}

Com o objetivo de examinarmos mais detidamente o significado das ações de Marcela, apresentaremos esse evento de letramento em duas sequências interacionais, em que a Marcela conversa sobre a escrita do seu nome com a professora (Tabela 2) e com a pesquisadora (Tabela 3). Essas tabelas estão organizadas da seguinte forma: na primeira e segunda colunas, numeram-se, respectivamente, as unidades de mensagem ${ }^{4}$ e o momento em 
que essas ocorreram (tempo registrado automaticamente pela câmera). A seguir, nas colunas ao lado, apresenta-se a transcrição das falas dos participantes. Na última coluna apresenta-se a descrição das ações dos participantes.

\section{Tabela 2}

Sequência Interacional I: O que é o diferente?

\begin{tabular}{|c|c|c|c|c|}
\hline Linhas & Tempo & Marcela & Professora & Açōes \\
\hline $\begin{array}{c}1 \\
2 \\
3 \\
4 \\
5 \\
6 \\
7 \\
8 \\
9 \\
10 \\
11 \\
12 \\
13 \\
14 \\
15 \\
16 \\
17 \\
18\end{array}$ & $26 \min 28 \mathrm{~s}$ & $\begin{array}{l}\text { tia } \\
\text { olha o } \\
\text { difere:::nte }\end{array}$ & $\begin{array}{l}\text { isso } \\
\text { mas eu falei } \\
\text { o quê? } \\
\text { que a gente } \\
\text { que a gente } \\
\text { iria pintar } \\
\text { com a } \\
\text { tinta } \\
\text { não foi isso } \\
\text { que a Júlia } \\
\text { falou? } \\
\text { pintar } \\
\text { com a tinta } \\
\text { vou preparar } \\
\text { a tinta }\end{array}$ & $\begin{array}{l}\text { A professora anda ao redor da mesa, } \\
\text { olhando os desenhos e conversando } \\
\text { com as crianças. } \\
\text { Júlia mostra o vestido da menina } \\
\text { colorido de amarelo, enquanto Marcela } \\
\text { mostra seu nome. }\end{array}$ \\
\hline
\end{tabular}

Conforme representado na Tabela 2, Marcela chama a professora Júlia, que observava a produção de seus alunos. Júlia se aproxima de Marcela, atendendo prontamente ao seu chamado, e inclina-se para conversar (quatro segundos foi o tempo entre ser chamada pela criança e responder - Tabela 2). Nesse momento, Marcela aponta para a escrita do seu nome em letra cursiva e diz: "tial olha ol difere:::nte". Sem alterar o seu tom de voz ou gesticular de maneira a sugerir impaciência, Júlia responde, apontando 
o vestido colorido de canetão: "issol mas eu faleil o que? que a gentel que a gentel iria pintarl com altinta".

De que maneira explicar o que acontece nessa conversa entre Marcela e a professora? Inicialmente, a professora denota aprovação do trabalho realizado por Marcela ao afirmar "isso". Entretanto, o questionamento que faz a seguir e o seu gesto apontando para o desenho indicarão que ela se referia ao desenho da aluna. Essas duas ações invalidariam, portanto, o comentário anterior ("isso") e deixaria claro que, do seu ponto de vista, Marcela não teria feito o combinado para a pintura. Professora e aluna se referiam, portanto, a objetos diferentes: desenho e escrita do nome, respectivamente.

Há nessa situação um exemplo bastante evidente do que Gumperz (1982) denominou de situações de mal-entendido. São aquelas que se originam de diferenças no enquadramento (COOK-GUMPERZ; GUMPERZ, 2011) utilizado por participantes para interpretar o que é dito por alguém ou o que acontece na situação da qual participam. Júlia interpreta o chamado e a fala da aluna do lugar de uma professora de artes, que acabara de propor uma nova técnica de pintura e, além disso, que não tem a escrita como objeto de ensino. Assim, ela desconsidera o que a aluna quer efetivamente lhe mostrar (a escrita do seu nome) e reafirma as orientaçôes dadas anteriormente: "mas eu faleil o quê?? que a gente iria pintar com tinta". Situações como essas são corriqueiras e podem ocorrer, e com frequência ocorrem, em qualquer conversa, dentro ou fora da escola. Não se trata aqui, portanto, de criticar a professora, mas de reconhecer as condições semióticas e sociais nas quais a comunicação entre ela e sua aluna aconteceu e examinar possíveis desdobramentos do ocorrido.

Marcela parece ter sido pega de surpresa pelo comentário da professora, já que não retoma o assunto com ela, confere o que os outros estão fazendo e retorna a trabalhar no seu desenho. Dessa forma, podemos ver que o comentário da professora reorienta a sua participação na oficina de arte. Mas teria Marcela de fato se dado por satisfeita e abandonado o objeto de seu interesse?

\section{Marcela explicita verbalmente o significado do "diferente”}

A segunda sequência interacional, constitutiva do evento de letramento protagonizado por Marcela, aconteceu quatro minutos após a sequência interacional analisada anteriormente e está representada na Tabela 3. Veremos 
Eventos interacionais e eventos de letramento...

que Marcela continua perseguindo o reconhecimento por um interlocutor adulto, dessa vez a pesquisadora, de que fez algo diferente em sua escrita.

\section{Tabela 3}

Sequência Interacional II: Meu nome está diferente

\begin{tabular}{|c|c|c|c|c|c|}
\hline Linhas & Tempo & Marcela & Pesquisadora & Miriam & Ações \\
\hline 1 & $30 \mathrm{~m} 57 \mathrm{~s}$ & tá prontinho & & & $\begin{array}{l}\text { Marcela } \\
\text { mostra seu } \\
\text { desenho para a } \\
\text { pesquisadora. }\end{array}$ \\
\hline 2 & & & quê que você & & \\
\hline 3 & & & desenhou aí & & \\
\hline 4 & & & Marcela? & & \\
\hline 5 & & & & Eu vou escrever & \\
\hline 6 & & & & Tárik & \\
\hline 7 & $31 \mathrm{~m} 05 \mathrm{~s}$ & meu nome & & & Marcela vira \\
\hline 8 & & tá diferente & & & a folha para si \\
\hline 9 & & achou? & & & $\begin{array}{l}\text { mesma e depois } \\
\text { mostra para a } \\
\text { pesquisadora. }\end{array}$ \\
\hline 10 & & & eu achei & & \\
\hline 11 & & & [só um minutinho & & Wanda \\
\hline 12 & & & Wanda...] & & mostra seu \\
\hline 13 & & & quê que você fez & & desenho para a \\
\hline 14 & & & ai de diferente? & & pesquisadora. \\
\hline 15 & $31 \mathrm{~m} 10 \mathrm{~s}$ & meu nome & & & \\
\hline 16 & & & pois é & & \\
\hline 17 & & & mas $Q U \hat{E}$ & & \\
\hline 18 & & & que ele tá & & \\
\hline 19 & & & diferente? & & \\
\hline 20 & & ele tá diferente & & & \\
\hline 21 & & ENTENDEU? & & & \\
\hline 22 & & & ele tá de & & \\
\hline 23 & & & letra como? & & \\
\hline 24 & & & não entendi & & \\
\hline
\end{tabular}




\begin{tabular}{|c|c|c|c|}
\hline $\begin{array}{l}25 \\
26 \\
27 \\
28 \\
29 \\
30 \\
31\end{array}$ & $31 \mathrm{~m} 20 \mathrm{~s}$ & $\begin{array}{l}\text { 'M'tá aqui } \\
\text { 'A' } \\
\text { mais 'R' tá } \\
\text { aqui } \\
\text { 'C' tá aqui } \\
o \text { 'E' aqui } \\
\text { o 'L'aqui } \\
\text { 'A' aqui }\end{array}$ & $\begin{array}{l}\text { Passa o dedo } \\
\text { pelas letras. }\end{array}$ \\
\hline
\end{tabular}

Como se vê representado na Tabela 3, Marcela busca, novamente, a atenção do seu interlocutor, dessa vez dizendo: "tá prontinho". Em resposta a esse comentário, ela ouve da pesquisadora: "quê que vocêl desenhou aíl Marcela?". Como aconteceu com a professora, a pergunta da pesquisadora indica que ela se orientava para o desenho e não para o registro escrito feito por Marcela. Dessa forma, podemos dizer que a pesquisadora compartilhava, pelo menos parcialmente, o enquadramento da professora ao supor e interpretar o que a aluna poderia lhe dizer naquele momento.

Entretanto, dessa vez, ao receber uma resposta que não lhe pareceu satisfatória, Marcela replica: “meu nomel tá diferentel achou?". Marcela explicita, então, verbalmente, o que do seu ponto de vista deveria ser o tópico da conversa entre ela e a pesquisadora. A contraposição entre a primeira e a segunda sequência interacional constitutivas desse evento de letramento nos permite ver como Marcela, tendo vivido a primeira situação de incompreensão com a professora, lança mão, em uma nova situação, de outros recursos discursivos para alcançar seu objetivo. Nesse caso, ela recorre à explicitação verbal ("meu nome tá diferente") e ainda busca conferir se a pesquisadora pode ver o "objeto" a que ela se refere (“achou?") (linhas 25 a 31 da Tabela 3).

A análise desse evento de letramento permite compreender a situação da seguinte forma: o que poderia ser considerado, apressadamente, como uma "falha" da professora teve origem nas condições sociais estabelecidas naquele contexto, condições estas também implicadas na resposta da pesquisadora. Essa análise também evidencia como Marcela persiste em se fazer compreendida pelos outros e em tornar a escrita parte integrante da interação entre ela e outros participantes da turma. 


\section{Considerações finais}

As análises apresentadas nesse texto permitiram conhecer alguns elementos das condiçōes sociais e semióticas que caracterizam as interações entre os participantes e a presença da escrita em uma turma de educação infantil de uma escola pública de Belo Horizonte. A contraposição de diferentes formas de representação e análises de um dia de aula, na turma observada, possibilitou identificar eventos de letramento que tiveram ora a professora, ora os alunos como agentes que tornavam a escrita integrante das interações estabelecidas entre participantes em sala de aula.

Foi evidenciado que a ação de um participante ou grupo de participantes (ou as suas reações ao que é falado ou feito por outros participantes) expressa as maneiras particulares como compreendem o que está acontecendo no contexto de que participam. Vimos, por exemplo, que os alunos, ao falarem em "coro" na aula de artes, evocaram e puseram em ação uma prática escolar que não havia sido solicitada pela professora. Vimos também que a resposta da professora e da pesquisadora à aluna que buscava tornar a escrita o tema de suas conversas foi orientada pela visão e expectativa que tinham do que seria "objeto de ensino" na aula de artes.

A análise do evento de letramento protagonizado por Marcela permitiu conhecer alguns aspectos do processo de inserção de uma criança em uma instituição de educação infantil, as demandas e expectativas que lhe são apresentadas e as demandas e expectativas que essas também podem apresentar aos outros participantes dessa instituição. A ação de Marcela exemplifica a ação de vários alunos que se empenharam, em momentos e formas variados, a tornar a escrita parte integrante das interaçōes estabelecidas no dia a dia da escola de educação infantil. No caso específico da turma investigada, houve um esforço das crianças em construírem identidades letradas, ou seja, identidades nas quais as práticas sociais de leitura e escrita tornaram-se centrais para cada uma delas e também para seu grupo geracional. Como Marcela, outras crianças desse grupo desejaram tomar para si a escrita e a leitura, tornando-as constitutivas de suas identidades pessoais e coletivas.

Gostaríamos de destacar algumas implicações de nossa análise para a discussão sobre o lugar da escrita na educação infantil. Reconhecemos o que já vem sendo feito por profissionais da educação infantil para propiciar o contato da criança com a escrita de maneira contextualizada (conforme se viu a professora de artes fazendo, ao trazer jornais e revistas para a sala 
de aula). Entretanto, julgamos que o interesse e empenho das crianças em tornarem a escrita parte integrante das interaçôes estabelecidas em sala de aula não podem ser subestimados ou negligenciados. Devemos prosseguir no exame de como essa demanda tem sido respondida por professores e outros profissionais da educação infantil, de maneira a criar condiçôes mais favoráveis à inserção da criança no mundo letrado.

\section{Notas}

1. A expressão eventos expressivos foi proposta como alternativa de tradução para o conceito de telling case proposto por Mitchell (1984).

2. Eventos interacionais referem-se a qualquer situação de fala (Hymes, 1972); um evento de letramento é qualquer situação de fala em que um suporte escrito torna-se integrante dos processos interativos entre participantes (Heath, 1983). Um mapa de eventos interacionais representa o que, quando e onde os sujeitos desenvolveram suas atividades. Os eventos interacionais são delimitados, retrospectivamente, por um conjunto de aspectos, dentre eles, a análise da relação semântica entre tópicos de conversa entre participantes e da reorganização dos espaços interacionais (Heras, 1993).

3. Aqui diferenciamos local de espaço interacional. $\mathrm{O}$ primeiro refere-se ao espaço físico onde o encontro entre participantes se dá. O segundo se refere à maneira como as pessoas se posicionam uma em relação às outras ou se organizam para desenvolverem suas atividades.

4. A unidade de mensagem é definida como a unidade de significado linguístico demarcada pelos limites da emissão identificados por meio de sinais contextualizadores, como a tonicidade, entonação, pausas e gestos , não sendo consideradas as formas gramaticais da escrita na transcrição (Gumperz, 1982). Assim, cada pausa ou mudança de entonação marca o início de uma nova unidade de mensagem, o que significa uma nova linha na transcrição ou uma barra (/). As letras maiúsculas indicam a mudança de entonação, os dois pontos (:::) indicam o prolongamento da vogal e os parêntesis duplos indicam os gestos.

\section{Referências}

BRANDĀO, A.C.P.; ROSA, E.C.S. (Org.). Ler e escrever na educação infantil. Belo Horizonte: Autêntica, 2010.

BRASIL. Lei 11.274, de 6 de fevereiro de 2006. Altera a redação dos arts. 29, 30, 32 e 87 da Lei n. 9.394, de 20 de dezembro de 1996, dispondo sobre a duração de 9 anos para o ensino fundamental, com matrícula obrigatória a partir dos 6 anos de idade. Diário Oficial da Uniāo, Brasília, DF, 7 fev. 2006.

BRASIL. Lei 12.796, de 4 de abril de 2013. Altera a Lei n. 9.394, de 20 de dezembro de 1996, que estabelece as diretrizes e bases da educação

Disponível em <http://www.cedes.unicamp.br> 
nacional, para dispor sobre a formação dos profissionais da educação e dar outras providências. Diário Oficial da Uniāo, Brasília, DF, 05 abr. 2013.

BRASIL. Ministério da Educação. Resolução CNE/CEB n. 5, de 17 de dezembro de 2009. Fixa as diretrizes curriculares nacionais para a educação infantil. Diário Oficial da União, Brasília, DF, 17 dez. 2009a.

BRASIL. Ministério da Educação. Secretaria de Educação Básica. Programa Currículo em Movimento. Brasília, DF, $2009 \mathrm{~b}$.

CAMPOS, M.M. Ensino fundamental e os desafios da Lei 11.274/2006. In: BRASIL. Ministério da Educação. Secretaria de Educação à Distância. Anos iniciais do ensino fundamental. Brasília, DF: MEC/SED, 2009. p. $10-16$.

CASTANHEIRA, M.L. Da escrita no cotidiano à escrita escolar. Revista Leitura: Teoria e Prática, Campinas, n. 20, p. 35-42, 1991.

CASTANHEIRA, M.L. Aprendizagem contextualizada: discursos e inclusão na sala de aula. Belo Horizonte: Ceale; Autêntica, 2004.

CASTANHEIRA, M.L. et al. Interactional ethnography: an approach to studying the social construction of literate practices. Linguistics and Education, v. 11, n. 4, p. 353-400, 2001.

COOK-GUMPERZ, J.; GUMPERZ, J. Frames and contexts: another look at the macromicro link. Pragmatics, Antwerp, v. 21, n. 2, p. 283-286, 2011.

CORSARO, W. The sociology of childhood. 2. ed. London: Sage, 2005.

GUMPERZ, J. (Ed.). Language and social identity. Cambridge, Mass: Cambridge University, 1982.

GUMPERZ, J. Convenções de contextualização. In: RIBEIRO, B.T.; GARCEZ, P.M. (Org.). Sociolinguística interacional. São Paulo: Loyola, 2002. p. 149-182.

HEATH, S.B. Ways with words: language, life, and work in communities and classrooms. Cambridge, Mass: Cambridge University, 1983.

HERAS, A.I. The construction of understanding in a sixth grade bilingual classroom. Linguistics and Education, Norwood, v. 5, n. 3/4, 1993. 
HYMES, D. On communicative competence. In: PRIDE, J.B.; HOLMES, J. Sociolinguistics. London: Penguin, 1972.

KRAMER, S. O papel da educação infantil na formação do leitor: descompassos entre as políticas, as práticas e a produção acadêmica. In: DALBEN, A. et al. (Org.). Convergências e tensões no campo da formação e do trabalho docente. Belo Horizonte: Autêntica, 2010. p. 111-133.

MITCHELL, J.C. Case studies. In: ELLEN, R.F. Ethnographic research: a guide to general conduct. Orlando: Academic, 1984. p. 237-241.

NEVES, V.F.A. Tensôes contemporâneas no processo de passagem da educação infantil para o ensino fundamental: um estudo de caso em Belo Horizonte. 2010. Tese (Doutorado em Educação) - Universidade Federal de Minas Gerais, Belo Horizonte.

NEVES, V.F.A.; GOUVÊA, M.C.S.; CASTANHEIRA, M.L. A passagem da educação infantil para o ensino fundamental: tensões contemporâneas. Educação \& Pesquisa, São Paulo, v. 37, n. 1, p. 121-140, jan./abr. 2011.

STREET, B. Literacy in theory and practice. Cambridge, Mass: Cambridge University, 1984.

STREET, B. Literacies across educational contexts. Philadelphia: Caslon, 2005.

Recebido em 30 de setembro de 2012.

Aprovado em $1^{\circ}$ de março de 2013. 